\title{
Alvaro Cepeda Samudio: \\ Del movimiento interrum pido a las formas en serie
}

Resumen: En el contexto de la urbanización emprendida en las principales ciudades atinoamericanas a partir de la década de los veinte, según se señala en este artículo, alvaro Cepeda Samudio incorpora a su narrativa "técnicas, escenarios y sensaciones modernos" que le confieren a su obra un efecto innovador. En el presente artículo se examinan brevemente dos libros de cuentos, Todos estábamos a la espera y Los cuentos de Juana, escritos por Cepeda en 1954 y 1972 respectivamente. Se hace un recuento de las distintas líneas narrativas empleadas por el autor en cada uno de sus cuentos, prestándole particular atención a la utilización de técnicas cinematográficas, a la interacción de la detención y las imágenes en movimiento y a la presentación de formas seriadas como motivos dominantes en sus relatos.

Palabras clave: cuento colombiano, urbanismo.

Abstract: Within the context of accelerated urbanization that took place in the most important cities of Latin America since the twenties, Álvaro Cepeda Samudio incorporated "modern techniques, settings, and feelings" into his narrative, conferring to it an innovative effect. Two of his works, Todos estábamos a la espera (1954) and Los cuentos de Juana (1972), are briefly analyzed in this article. The author examines the different narrative modes used by Cepeda in his shortstories, giving particular attention to the utilization of narrative techniques, to the interaction between immobility and images in motion, and to the presentation of serialized forms as predominating motifs in his stories.

El ambiente

En los años cincuenta ocurrió el lanzamiento definitivo del proceso de urbanización acelerada en Colombia comenzado en los veinte. En pocas décadas, las ciudades crecieron multiplicando su tamaño por cinco o seis. Cada vez se disipaban más el centro o la distancia desde los que podía mirarse el conjunto; todo tendía a situarse encima de los ojos y, por lo mismo, se tendía a percibir por acumulación, en espacios reducidos. Se sustituía atropelladamente la percepción estacionaria del tiempo por una decreciente velocidad $\mathrm{y}$, culturalmente, la atención se volcaba hacia los Estados Unidos.

La nueva ambientación comportaba una sensibilidad propia que, a su vez, quiso reflejarse en la escritura. Sus primeros reflejos narrativos se dan en Barranquilla—un puerto-con Álvaro Cepeda Samudio y en Cali- vinculada a un 
puerto, Buenaventura-con Andrés Caicedo. Por esos puertos entró la literatura norteamericana-y, en general, la anglosajona, que reemplaza a las influencias francesa y española precedentes: Faulkner, Dos Passos, Steinbeck, Hemingway, Capote; a Cali llegarán también Hawthorne, Melville, H.P. Lovecraft.

La detención: Todos estábamos a la espera

El Grupo de Barranquilla inicia en general un proceso de liberaciones formales que con Cepeda se orienta a vincular la literatura colombiana con técnicas y escenarios actuales.

Cepeda nació en 1926. Pertenece, por tanto,-como García Márquez-a la generación de la primera urbanización de los años veinte. En 1936 se trasladó a vivir a Barranquilla y en 1949 viajó a Nueva York a estudiar periodismo. A su regreso publicó Todos estábamos a la espera (1954). La procedencia de los personajes y de la ambientación es manifiesta en el libro, así como lo son las lecturas de las que se nutría el autor. En el epígrafe general, él declara haber vis to a sus personajes "en un pequeño bar de Alma, Michigan; es perando en una estación de Chattanooga, Tennessee; o simplemente viviendo en Ciénaga, Magdalena", y declara, además, haber escrito la mayoría de los cuentos en Nueva York, identificada como una ciudad sola, bajo la forma de la soledad-sin solución-de la espera. Todos los epígrafes, en inglés, que a lo largo del libro preceden a algunos de los textos, son de Saroyan, James Jones, Truman Capote y Faulkner.

De los 12 cuentos que confoman el libro, la mitad transcurren directamente en bares o en un deambular que tarde o temprano lleva a los personajes a recalar en algún bar. Sin explicaciones, sin grietas de pensamiento, en una detención vital que abre y alarga los instantes, los personajes dejan con serenidad que su soledad se desborde en medio de la acción externa, a veces impulsados a moverse sin querer llegar a alguna parte, como en "Hoy decidí vestime de payaso"-decididamente el más bello y singular del libro y sin duda uno de los mejores cuentos colombianos en la segunda mitad del siglo?, o tachonados al ambiente mismo, al ruido, al trajín del bar, como en el onomatopéyico "Tap-room".

En otro grupo, de ambiente intimista, de historias sugeridas, tomadas en un corte dentro de la fluencia, se revela la detención que lentamente romperá el movimiento. La atención se concentra en los objetos, en los elementos más próximos al observador que despierta. En "Proyecto para la biografía de una mujer sin tiempo", los objetos se hallan ante la incertidumbre de la luz, que en principio no se sabe si entra o huye de la habitación. En este ambiente, el menor cambio - el sólo correr de las láminas de la persiana por medio de las cuerdasse involucra con el movimiento cotidiano que todo lo absorbe. O, en "Intimismo", se muestra sólo el lento despertar: la nada anterior y el movimiento que es imposible decir cuánto durará, la aparición de las sensaciones y la apertura de instantes, como el inicio de lo que sólo más tarde, al hablar, podrá ser medido, pensado, narrado. 
Insular respecto a esos grupos de cuentos, resalta por su particularidad "Vamos a matar los gaticos", construido sólo con el diálogo de los niños que se disponen a matar los gaticos recién nacidos para que no los regalen. Es te tipo de historia y esta técnica están distantes del resto del libro, pero ambos hallarán un lugar más nítido en los libros posteriores de Cepeda.

\section{La acción: Los cuentos de Juana}

Con su única novela propuesta como tal, La casa grande (1962), Cepeda efectuó un cambio radical de escenario: de los ambientes citadinos pasó a la huelga de 1928 en las bananeras, un tema histórico nacional. Pero, para ello recurrió a la acumulación de fragmentos, a una especie de montaje de escenas, un collage de instantes e imágenes que incluye el texto mismo del decreto oficial 4 del 16 de diciembre de 1928. Manifiestamente sustentado en la técnica tan importante en la literatura norteamericana desde Moby Dick, la his toria se articula al modo de la composición cinematográfica, con lo cual el texto, a veces abstruso, se penetra de un sentido de libertad formal y creativa que determina su gran eficacia.

En Los cuentos de Juana (1972) se ahonda en ese sentido de libertad. Es una colección de 21 textos que funcionan lo mismo como cuentos plenamente autos uficientes que como capítulos de una única his toria. Así, el libro navega con suficiencia entre la reunión de cuentos fantásticos y la novela corta no convencional, en uno y otro caso en torno a Juana-por momentos claramente gringa, pero habitante de Ciénaga, de Barranquilla, de Sabanilla $-\mathrm{y}$ a su particular sentido mágico de develar el entorno, vista ella en diferentes momentos de su existencia. Resalta, por lo demás, que tanto el texto que abre el libro, "Las muñecas que hace Juana no tienen ojos", como el que lo cierra, "Barranquilla en domingo...", entroncan temáticamente con la casa grande -remembranzas directas a su ambiente, perpetuación de los afectos y el odio, en el primero, y Juana que sale de allí vestida de novia, finalizando el último. Ambos se construyen cinematográficamente: el primero como un guión que desarrolla la escena para la cámara; el otro, como una sucesión de tomas o breves escenas, a continuación del suicidio de Juana, que rememoran en rápidas imágenes el libro y la vida de Juana, y que son en realidad una serie de flas $\mathrm{h}$-backs.

Al centro del libro se destaca "El ahogado", una historia común a García Márquez-“El ahogado más hermoso del mundo" (1968), pero mientras en éste se impone la fábula extraordinaria, en aquél lo hace la imagen en movimiento. El mismo texto se anuncia como "la versión argumental para un mediometraje"1 que - descubrimos - va siendo leída y comentada con soma por una mujer, recurso con el cual se impide la solemnidad. En la primera toma, la cámara muestra al ahogado por debajo, desde el agua; se mueve lentamente, sale a la

\footnotetext{
${ }^{1}$ A esta altura es oportuno recordar que Cepeda mismo se había metido de tiempo atrás en el celuloide. Hacia 1955 había realizado $L a$ langosta azul .
} 
superficie, se eleva hasta la panorámica y, en adelante, a gran ritmo, todo se muestra con sus movimientos, en conjunción con el sonido: el ruido del motor de la lancha en la que se recoge al ahogado y se lo lleva por la ciénaga has ta arrojarlo en la desembocadura para que salga al mar. Son el movimiento y el sonido ininterrumpidos, que a su vez dan cuenta de la acción permanente, de la velocidad de la lancha, lo que da tensión al relato. El intenso movimiento, que rompe el ambiente de monotonía de la ciénaga, se constituye así en el centro de la narración.

Otras historias, por su parte, se internan en la cotidianidad, rompiéndola con la fantasía. Por ejemplo, en "Des de que compró la cerbatana ya Juana no se aburre los domingos" (porque se distrae matando des de el edificio de frente al estadio tres o cuatro jugadores cada vez con los dardos envenenados de su cerbatana) el escenario son los domingos de fútbol en Barranquilla, ciudad a donde Juana se ha trasladado. Cuentos cercanos a éste son "Desde que comenzaron a recortarle..." las patas a todos los muebles de la casa, "Juana tenía..." el pelo de oro, "Sabanilla", donde desaparece la mujer que se roba los perros y los encuentran en su casa muertos y el ya nombrado "Barranquilla en domingo...".

O, en otra línea narrativa, la interioridad se refleja en instantes, en cortes tomados de una fluencia mayor e inexplicada y presentados a través de una narración convencional aunque con mezcla de puntos de vista particulares, como en "Ven enseguida..." y "Otra vez Juana (Final)", o mediante el diálogo depilado de cualquier acotación, como es el caso de "En este pueblo ya no canta la..." lechuza. De esta línea "Las muñecas que hace Juana no tienen ojos" representa un justo medio.

Pero entre esas líneas técnicas y temáticas destaca otra más novedosa, la de las formas seriadas a partir de elementos de la cotidianidad: la multiplicación sin fin de los cuáqueros en la serie de latas de avena Quaker, en "A García Márquez, Juana le oyó...". Otro ejemplo de esto es "Esta es la triste historia...", una brevísima y melodramática historia repetida tres veces, que en su repetición parodia la monotonía, y "Juana tiene una amiga...", culminación de un juego creador de formas artificiales que narra la historia de la amiga de Juana cuya distracción es comprar automóviles nuevos, desarmarlos y fabricar con las partes—sólo bota las llantas-flores de hierro.

En cualquier caso, descuella en Los cuentos de Juana el énfasis sobre la imagen en movimiento que, finalmente, mediante la observación desde ángulos parciales y no desde su totalidad, temina por sugerir las formas en serie generadas en un ambiente urbano. Asimismo, la variedad técnica y temática dota al libro-que apenas raya las cien páginas-de una riqueza estilística infrecuente en la literatura colombiana.

Siendo más bien desconocido, Los cuentos de Juana es uno de los libros más versátiles, menos clasificables y, sin duda, uno de los más interesantes de todos 
los escritos en Colombia en la segunda mitad del siglo XX. Por lo demás-aunque su recensión sigue siendo parcial? , con la totalidad de su obra Cepeda se distancia rotundamente de sus predecesores y contemporáneos en el país. Él actúa como introductor de liberaciones que abren la literatura colombiana a técnicas, escenarios y sensaciones modemos. Su distanciamiento empieza en los temas, pero se ha ce más os tensible en la manera de abordarlos, en la variedad y eficacia técnicas - en particular la cinematográfica-con las que los introduce. 